\title{
Foucault e a História da sexualidade: da multiplicidade das forças à biopolítica
}

\author{
Foucault and the History of sexuality: from the multiplicity \\ offorces to biopolitics
}

\section{Helton Adverse*}

Universidade Federal de Minas Gerais, UFMG, Belo Horizonte, MG, Brasil

\section{Resumo}

Por ocasião dos quarenta anos da publicação do primeiro volume da História da sexualidade - A vontade de saber, este trabalho tem por objetivo colocar em destaque seu caráter profundamente inovador, dando especial atenção a dois momentos do percurso que Foucault realiza no livro: a definição de poder como "multiplicidade de relações de forças" imanentes ao domínio político e o conceito de biopolítica. Esses dois pontos têm como pano de fundo comum a crítica ao discurso jurídico-político e, além disso, articulam uma concepção da política moderna extremamente original.

Palavras-chave: Foucault. Política. Soberania. Biopolítica.

\footnotetext{
* HA: Doutor em Filosofia, e-mail: heltonadverse@hotmail.com
} 


\section{Abstract}

After forty years of its publication, the first volume of Foucault's History of sexuality - An introduction is still a profoundly innovative work. This paper's aim is to elucidate some of its aspects, giving special attention to two points of Foucault's analyses. The first is the definition of power with terms like "multiplicity of force relations" and the second is the famous concept of biopolitics. In both points Foucault articulates his criticisms to the juridico-political discourse and formulates a very original conception of modern political experience.

Keywords: Foucault. Politics. Sovereignty. Biopolitics.

\section{Introdução}

O primeiro volume da História da sexualidade, publicado pela primeira vez há quarenta anos, é repleto de proposições, teses, ideias de enorme impacto: a crítica da "hipótese repressiva" e a adoção da "hipótese Nietzsche", a afirmação de que o Ocidente, em detrimento de uma ars erotica, empenhou-se em desenvolver uma scientia sexualis, a diferenciação entre os "dispositivos" de aliança e o de sexualidade, o surgimento de uma nova forma de poder que não apenas se incide sobre o corpo, mas também sobre a "população", assumindo como um de seus objetivos maiores a promoção da vida da espécie. Essas teses se sucedem, se entrecruzam, apoiam umas às outras em um ritmo surpreendente, conferindo ao livro uma densidade poucas vezes igualada na história da filosofia. Do conjunto dessas proposições desconcertantes e de forte teor filosófico, gostaria de reter duas, pois acredito que elas contribuem significativamente para a reformulação de nossas perspectivas teóricas. A primeira é a seguinte: “Por poder, parece-me que é possível compreender de início a multiplicidade das relações de força que são imanentes ao domínio onde elas se exercem, e são constitutivas de sua organização" (FOUCAULT, 1976, p. 121-2). E a segunda: “O homem, durante milênios, permaneceu o que era para Aristóteles: um animal que vive e, além do mais, capaz de uma existência política; o 
homem moderno é um animal na política do qual sua vida de ser vivo está em questão" (FOUCAULT, 1976, p. 188).

As duas frases citadas anteriormente, chamaram a atenção de vários comentadores. Afinal de contas, elas têm algo de escandaloso e paradoxal. No que concerne à primeira afirmação, Foucault parece encontrar o poder em todos os domínios da vida social: o poder, diz ele ainda, "está por toda parte"; e, em seguida, especifica: "não que ele englobe tudo, é que ele vem de toda parte" (FOUCAULT, 1976, p. 122). Ora, isso assinala uma "politização" da sociedade, que fere abertamente um dos princípios maiores do discurso jurídico-político: o de que o poder político é essencialmente atributo do Estado, logo, está sobretudo localizado no conjunto de aparelhos e instituições que o caracteriza, cifrando-se na forma da soberania. No que diz respeito à segunda, é justamente a "vida de ser vivo" que é identificada como "aquilo que está em jogo" (o enjeu) nas relações de poder na modernidade, ao passo que tradicionalmente ela é aquilo que deve ser resguardado, protegido e, em certa medida, conservado ao abrigo do poder político. O discurso jurídico-político parte do pressuposto de que o que qualifica o ser humano politicamente é precisamente o direito, seu status jurídico e não sua condição biológica.

Mas não é somente a concepção jurídica de poder que é questionada nessas proposições de Foucault. Na verdade, essas proposições têm um alcance maior, colocando em xeque a tradição do pensamento político. Não é sem razão a escolha de Aristóteles, na segunda passagem, visto ser ele o filósofo que, no interior dessa tradição, insistiu como poucos na distinção entre o espaço político e o espaço da casa, ou entre o público e o privado. Com efeito, para Aristóteles, o poder político, que os homens exercem na cidade, não se confunde com aquele exercido no interior do oikos (ARISTÓTELES, 1993, p. 85). E é também no âmbito da família (ou ao menos do vilarejo) que se estrutura a organização responsável pela manutenção da vida. Como vemos, a modernidade, para Foucault, contradiz Aristóteles duplamente: tanto na extensão do poder político quanto no objeto sobre o qual ele deve se incidir. O que eu gostaria de fazer neste texto é compreender como essas proposições se articulam no livro de Foucault 
e como, a partir delas, é possível salientar alguns dos aspectos mais originais da genealogia do poder.

\section{A Crítica ao Poder Soberano}

Antes de explorar as consequências de cada uma das proposições e o modo como elas estão articuladas, é importante sublinhar que ambas têm um alvo em comum: as teorias políticas que dão ênfase à noção de soberania, ou aquilo que em diversas ocasiões Foucault denominou de "discurso jurídico-político".

$\mathrm{Na}$ verdade, desde o começo de sua genealogia do poder Foucault chamava a atenção para a limitação da noção de soberania, ou seja, sua insuficiência para recobrir o campo de nossa experiência política. Assim, desde ao menos o ano de 1973 - como vemos no curso sobre a sociedade punitiva - , uma nova concepção do poder, não repressivo, não negativo, vem à luz, em contraste com a concepção repressiva clássica, vazada em termos jurídicos (FOUCAULT, 2013). Essa nova concepção de poder (o "poder disciplinar") será plenamente formalizada no curso sobre o poder psiquiátrico (FOUCAULT, 2006) e ganhará sua versão mais acabada em Vigiar e punir (FOUCAULT, 1975). Desnecessário reproduzir aqui todos os passos que levam, no âmbito da analítica do poder, a essa noção chave. Basta assinalar que o "poder disciplinar", diferentemente do "poder soberano", não se exerce "como uma propriedade, mas como uma estratégia" (FOUCAULT, 1975, p. 35), o que implica reconhecer que ele se situa no nível de uma "microfísica", que ele se "difunde em rede" (FOUCAULT, 1975, p. 36), que se imiscui nas diversas camadas da sociedade, não se deixando identificar com os aparelhos de Estado, mas informando-os, colocando-os em funcionamento e sendo por eles utilizado. Além disso, os efeitos de assujeitamento dessa forma de poder contrastam com a ação repressiva do poder soberano e apontam seu limite justamente no momento em que emerge a sociedade moderna, a sociedade disciplinar.

O que me parece relevante destacar é que nessa investigação, dedicada em grande ao sistema prisional, Foucault consegue formular o 
problema do poder em termos marcadamente positivos. Ele constrói algo como um "esquema interpretativo" em que o aspecto produtivo do poder é destacado por meio de um contraste com a concepção negativa. Esse esquema interpretativo é replicado em $A$ vontade de saber, mas em um contexto diferente (está agora em questão fazer a história de nossa relação com o sexo e com a sexualidade, e de como essas noções não podem ser desvencilhadas dos mecanismos de poder). Não surpreende, portanto, que o livro se inicie com o desmantelamento da "hipótese repressiva" para, em seguida, definir as linhas gerais da analítica do poder ${ }^{1}$. É imprescindível observar que esse movimento crítico, que marca o momento inicial da investigação, não somente prepara nosso olhar para uma nova modalidade de poder, mas mostra ainda que a concepção anterior (negativa) esconde ela própria uma natureza política. Assim, quando Foucault desfaz a imagem que tínhamos de nós mesmos em relação com a sexualidade, quando mostra que não estamos sob o signo da repressão puritana, que não somos os "vitorianos" que acreditávamos ser, desvela os benefícios que extraímos da adoção da hipótese repressiva. A imagem, diz ele, de que estamos, há mais de dois séculos, sob o efeito do rigor puritano, nos presta alguns serviços: ela "faz corpo com a dominação burguesa" (FOUCAULT, 1976, p. 12), ela rende o "benefício do locutor" (pois se o sexo é proibido, o mero fato de falar sobre ele constitui uma transgressão), a promessa de uma liberação, de uma supressão dos interditos que anunciaria uma nova época de prazer e liberdade (FOUCAULT, 1976, p. 14).

Denunciado esse sortilégio, é hora de mostrar que outra coisa está em jogo: sobre o sexo, nossa época não se cansa de falar, em uma “verdadeira explosão discursiva" (FOUCAULT, 1976, p. 25). Nada de silêncio, mas uma curiosidade incessante que torna necessária uma genealogia dessa vontade de saber sobre o sexo. Cabe a essa genealogia não desfazer a hipótese repressiva, como se fosse a bruma que nos impedisse de ver quem realmente somos, mas de restituir a positividade das relações de poder por detrás de sua aparente negatividade. A concepção negativa mascara o fato da dominação. Esta tese orienta

1 Encontramos esse mesmo procedimento metodológico nos cursos 0 poder psiquiátrico e É preciso defender a sociedade. 
toda a crítica de Foucault ao discurso jurídico-político, como vemos claramente exemplificado nessa passagem do curso de 1976, Em defesa da sociedade (a propósito do direito):

A teoria do direito tem essencialmente por papel, desde a Idade Média, fixar a legitimidade do poder: o problema maior, central, em torno do qual se organiza toda a teoria do direito é o problema da soberania. Dizer que o problema da soberania é o problema central do direito nas sociedades ocidentais significa que o discurso e a técnica do direito tiveram essencialmente por função dissolver, no interior do poder, o fato da dominação, para fazer aparecer no lugar desta dominação, que era desejável reduzir ou mascarar, duas coisas: de um lado, os direitos legítimos da soberania e, de outra parte, a obrigação legal da obediência. O sistema do direito está inteiramente centrado sobre o rei, quer dizer que ele é a eviç̧ão do fato da dominação e de suas consequências (FOUCAULT, 1997, p. 21).

Como podemos ver, a crítica da hipótese repressiva aplica esse mesmo modelo, que permite a Foucault colocar a concepção jurídica do poder no quadro mais geral de uma teoria do poder entendido como conflito. A negatividade da hipótese repressiva deve ser integrada no conjunto dos mecanismos que nos incitam a discorrer sobre o sexo a fim de extrair uma verdade sobre nós mesmos com efeito de subjetivação. Em suma, a hipótese repressiva deve ser inserida no dispositivo de sexualidade:

O segredo do sexo não é, sem dúvida, a realidade fundamental com relação à qual se situam todas as incitações a dele falar - que elas tentem quebrá-lo ou, de maneira obscura, o reconduzam pela próprio modo com que falam. Trata-se antes de um tema que faz parte da própria mecânica das incitações: uma maneira de dar forma à exigência de falar dele, uma fábula indispensável para a economia indefinidamente proliferante do discurso sobre o sexo. O que é próprio das sociedades modernas não é que elas tenham destinado o sexo a permanecer na sombra, é que elas tenham se dedicado a falar dele sempre, fazendo-o valer como $o$ segredo (FOUCAULT, 1976, p. 48-9). 
Que Foucault esteja plenamente consciente de que sua crítica da hipótese repressiva reitera aquela da soberania não há qualquer dúvida. Para ser mais preciso, devo lembrar que ele associa uma coisa à outra logo no começo da quarta parte do livro: a necessidade de livrar-se de uma representação do poder do tipo "jurídico-discursiva" também alimenta a crítica às representações - incluindo aí a psicanálise - segundo as quais a lei é constitutiva do desejo, último baluarte da hipótese repressiva. Essas críticas serão sintetizadas na conhecida fórmula: "Pensar ao mesmo tempo o sexo sem a lei e o poder sem o rei" (FOUCAULT, 1976, p. 120).

Gostaria de deixar claro o que desejo afirmar para poder avançar as próximas seções deste texto: ao privilegiar o aspecto positivo do poder, Foucault sempre ressalta sua materialidade. E essa perspectiva parece ser ampla o suficiente para englobar mesmo as definições negativas do poder. Isso não significa que a concepção negativa se reduza a um mero efeito de superfície, uma ilusão ou um mascaramento (embora, como vimos, Foucault às vezes a entenda como tal); afinal de contas, o poder se exerce igualmente na chave repressiva - ele também diz "não". Mas o que Foucault parece dizer é que essa negatividade pode ser rebatida sobre um pano de fundo positivo, ou sobre uma positividade. Dizendo de outra maneira, Foucault se interessou, ao menos a partir de 1973, em examinar essa dimensão positiva, ou ainda, o modo por meio do qual o poder constrói nossa realidade agindo no nível da materialidade 2 . Por isso Foucault muito rapidamente abandonou a pesquisa sobre o aspecto representativo do poder ${ }^{3}$. A seguinte passagem de uma entrevista bastante conhecida, de 1977, é esclarecedora: "O que eu busco é tentar mostrar como as relações de poder podem passar materialmente na espessura mesma dos corpos sem ter de

2 Duplo sentido, portanto, do termo "positividade": por um lado, o termo evoca os trabalhos de Foucault desde os anos 1960 quando, especificamente na Arqueologia do saber, 0 definia como o "regime discursivo ao qual pertenciam as condições de exercício da função enunciativa". 0 que estava em jogo então era que as condições de validade de um saber não necessitavam ser referidas à totalidade da significação nem à interioridade de um sujeito (FOUCAULT, 1969, p. 164). Por outro lado, 0 "positivo" adquire o significado de "produtivo", como é mais frequente no contexto da analítica do poder (FOUCAULT, 1976, pp. 16 e 113). Minha sugestão é a de que não podemos compreender um sentido sem ter em mente 0 outro.

3 Esse ainda era um dos focos de seu interesse em 1972, como podemos ver no curso sobre as teorias e as instituições penais (FOUCAULT, 2015a, p. 235-41). 
ser transmitidas pela representação dos sujeitos" (FOUCAULT, 1994, p. 231). Ora, nesse registro - o da "materialidade dos corpos" - o poder é plenamente positivo: ele "circula", ele "passa", ele opera em rede. E talvez tenha sido Gilles Deleuze que melhor tenha compreendido sua natureza: a definição de poder de Foucault é muito simples: "ele é uma relação de forças" (DELEUZE, 1986, p. 77). Como tal, ele não pode se aplicar, circular, passar a não ser sobre os corpos, o que vale igualmente para o poder do Estado: "Para que o Estado funcione como funciona, é preciso que haja do homem à mulher ou do adulto à criança relações de dominação bem específicas, que têm sua configuração própria e sua relativa autonomia" (FOUCAULT, 1994, p. 232).

Delimitado o escopo preciso da crítica à soberania, podemos voltar às duas proposições que destacamos anteriormente.

\section{Poder: um Jogo de Forças}

$\mathrm{O}$ ano em que Foucault publica $A$ vontade de saber é o mesmo em que havia dado o curso Em defesa da sociedade, no qual, como é sabido, propõe a inversão da fórmula de von Clausewitz "a guerra é a continuação da política por outros meios". Foucault acredita que "a política é a guerra continuada por outros meios" (FOUCAULT, 1997, p.16) - frase que, de resto, é repetida em A vontade de saber (FOUCAULT, 1976, p. 123). Mas desde pelo menos o curso sobre $A$ sociedade punitiva o "modelo bélico" era mobilizado por Foucault para pensar as relações de poder. É igualmente bastante conhecido a distância que ele vai tomar, mais tarde, com relação a esse modelo, preferindo - não sem abandonar, contudo, a perspectiva conflitiva, a noção de estratégia, de tática - pensar o poder em termos de "governo". Nada mais natural, e respaldado pelos textos, do que colocar sob a égide do belicismo, do agonismo o pensamento político o qual coloca em evidência o tema da força. Mas tenho a impressão de que Foucault faz mais do que isso; creio que ele faz mais do que simplesmente engrossar a fileira dos autores que entendem a política na chave do conflito (diga-se 
de passagem, uma tradição com nomes de peso: Maquiavel, Hobbes, Schmitt, Lefort ${ }^{4}$ ): assim como havia purgado o saber e a história de todo elemento transcendente (como a noção de consciência ou de sujeito), tomando-os em sua "singularidade pura", agora o poder aparece em sua "positividade" como um campo de lutas irredutíveis às intenções ou à consciência dos sujeitos, e cuja natureza é somente obscurecida pela noção de "ideologia". Por isso, o registro em que as lutas se travam - ao menos o registro que interessa a Foucault examinar - não é aquele que concerne diretamente à estrutura social em sua totalidade, mas aquele que ele chama de "local". Para entender melhor esse ponto, é necessário voltar ao texto.

Foucault define o poder, como vimos, como "multiplicidade de relações de força imanentes ao campo em que elas se exercem". Em seguida, ele afirma que o poder é também "o jogo que, por via de lutas e enfrentamentos incessantes, as transforma, as reforça, as inverte"; ele é, ainda, "os apoios que essas relações de força encontram umas nas outras, de maneira a formar cadeia ou sistema, ou, ao contrário, os deslocamentos, as contradições que as isolam umas das outras". Por fim, o poder implica as estratégias "nas quais elas adquirem efeito, e cujo desígnio geral ou a cristalização institucional ganham corpo nos aparelhos estatais, na formulação da lei, nas hegemonias sociais" FOUCAULT, 1976, p. 121-2). Multiplicidade, jogo, apoios, estratégias que se efetivam, que são colocados em práticas e estruturam o campo social não a partir de um ponto central, mas a partir da "base móbil das relações de força que induzem sem cessar, por sua desigualdade, estados de poder, mas sempre locais e instáveis" (FOUCAULT, 1976, p. 122).

Se as relações de poder são "instáveis" e "locais" de nada nos serve tentar apreendê-las a partir de um ponto de vista globalizante. $\mathrm{Na}$ verdade, a genealogia do poder assinala se não a impossibilidade desse ponto de vista, ao menos seu desinteresse. Em certa ocasião, Paul Veyne definiu essa genealogia em termos esclarecedores: "a história genealógica não é uma filosofia, ela estuda os fenômenos empíricos e não pretende descobrir a verdade total" (VEYNE, 2008, p. 127).

4 Muito embora Foucault não considerasse Maquiavel e Hobbes "teóricos da guerra na sociedade civil" (FOUCAULT, 1997, p. 19). 
Embora, creio, Veyne tenha uma visão por demais restrita da filosofia, ele acerta em cheio quando destaca o caráter não totalizante, avesso à sistematicidade conceitual que marca a genealogia. Ao mesmo tempo, Veyne chama a atenção para a natureza "empírica" da pesquisa, o que se prende à "positividade" de que falei mais acima. Se a analítica do poder toma as relações de poder nesse nível, então seria incoerente fundar, sobre ela, uma nova teoria do poder. Concordo inteiramente com Arnault Skornicki quando afirma: "a analítica do poder, como seu nome o indica, é exatamente o contrário de uma ontologia do social e da política” (SKORNICKI, 2015, p. 36).

Furtando-se do "impulso totalizante" da teoria, Foucault não pode deixar de afirmar a "imanência" das relações de poder "ao domínio em que são exercidas", reiterando, no registro conceitual, o mesmo gesto com que assume a fragmentação e a instabilidade no registro empírico. Mas o que Foucault quer dizer com o termo "imanência"?

[...] as relações de poder não estão em posição de exterioridade a respeito de outros tipos de relação (processos econômicos, relações de conhecimento, relações sexuais), mas que elas lhe são imanentes; elas são os efeitos imediatos da partilha, das desigualdades e dos desequilíbrios que aí se produzem, e elas são reciprocamente as condições internas dessas diferenciações; as relações de poder não estão em posições de superestrutura, com um simples papel de proibição ou de recondução; ela têm, aí onde atuam, um papel diretamente produtor (FOUCAULT, 1976, p. 123-4).

Gostaria de esmiuçar um pouco essa passagem: a imanência de que fala Foucault pouco tem a ver com o sentido que o termo adquiriu na tradição filosófica, especificamente, aquela que vai de Spinoza a Deleuze. Alguns comentadores, como Serge Audier, lembraram a origem deleuziana do termo (AUDIER, 2015, p. 142-3), o que me parece bastante plausível. Porém, creio que Foucault o utilize em sentido diverso, onde o que está em questão é simplesmente o fato de que as relações de poder se fazem presentes nos outros domínios de atividade, como a economia ou o conhecimento. Aliás, essa é uma ideia que ele 
havia avançado no curso de 1972, Teorias e instituições penais, onde em uma nota ele escreve o seguinte:

as relações de poder não se sobrepõem às relações econômicas. Eles formam com elas uma trama única. As relações de poder são tão profundas quanto as relações de produção. Elas não são deduzidas umas da outras. Elas reconduzem umas às outras (FOUCAULT, 2015a, p. 172).

Ora, não é difícil perceber que com a noção de "imanência", tanto em 1972 quanto em 1976, Foucault defere uma crítica contra o marxismo, por um lado. Por outro lado, mantém-se fiel a seu pressuposto metodológico fundamental: não abandonar o campo das "empiricidades", da positividade. Sendo assim, o poder não é algo que se acrescenta às coisas, algo que vem de fora, um atributo do sujeito que ele teria a liberdade de utilizar ou de se abster, de transmitir ou guardar para si. E, no entanto, não é também uma qualidade das coisas, uma objetividade plena que o termo "força" poderia fazer entender. O poder se constitui na "relação" entre os sujeitos (FOUCAULT, 1976, p. 126). Esta relação não implica necessariamente acordo, harmonia ou consenso, pelo contrário. Inúmeras vezes Foucault insistiu em seu caráter "tático", chamou a atenção para as estratégias que são mobilizadas nesse enfrentamento, como vimos. Em suma, a "relação" deve ser compreendida sob a égide do conflito e da luta. Mas o que valeria a pena destacar nesse momento é que, não podendo ser identificado com uma propriedade subjetiva, o poder ao mesmo tempo produz assujeitamentos e "desassujeitamentos"; ; ao mesmo tempo em que estrutura as relações sociais, familiares e pessoais, abre a possibilidade para sua reorganização, para uma nova distribuição das posições que os sujeitos aí ocupam. Afinal de contas, como afirma Foucault, “onde há poder, há resistência" (FOUCAULT, 1976, p. 125).

No entanto, há ainda outra coisa que seria conveniente reter: a disseminação das relações de poder por toda a sociedade anda junto

5 Termo que aparecerá mais frequentemente nos trabalhos de Foucault a partir de 1978. Ver, por exemplo, a famosa conferência para a Sociedade Francesa de Filosofia (FOUCAULT, 2015b, p. 42). 
de sua natureza "positiva", tanto no sentido da produtividade quanto no da materialidade. Se o corpo do indivíduo, como quer Foucault, é perpassado pelo poder, todo o corpo social está igualmente submetido ao jogo das forças em conflito. E, da mesma forma que o poder produz subjetividades - no nível individual - , ele produz efeitos globais, agindo sobre o conjunto dos membros de uma comunidade política. No primeiro caso, o sistema do poder necessita colocar em prática os mecanismos que asseguram, sobretudo na forma das "disciplinas", o controle sobre o indivíduo. No segundo caso, são necessários mecanismos que permitam a intervenção sobre os indivíduos tomados como membros de uma espécie, como parte de um todo, isto é, aquilo que Foucault denomina de "população" (posteriormente, Foucault escolherá o nome de "dispositivo de segurança" para designar essa nova tecnologia política). O reconhecimento desses diferentes níveis em que se exercem os dispositivos de poder nada tem a ver com uma restituição de uma perspectiva totalizante na política. Trata-se somente de extrair as consequências do pressuposto de que o poder "está em toda parte", o que exige que sua analítica também contemple um nível "macro". Ora, um dos problemas maiores que Foucault examina no livro de 1976 é compreender como é possível passar de uma "microfísica" do poder a uma "macrofísica", como se passa do corpo individual ao corpo coletivo. A sexualidade é precisamente o que articula uma coisa à outra e é graças à sua "mediação" que a genealogia pode explorar um novo domínio, que ganhará então o nome de "biopolítica", um conjunto de relações de poder que tem por objeto a população.

Antes de abordar diretamente o tema da biopolítica, gostaria apenas de recordar alguns passos da argumentação de Foucault que explica como a sexualidade pôde cumprir essa função.

\section{Entre o corpo do indivíduo e o corpo da população}

A sexualidade, diz Foucault, "aparece como um ponto de passagem particularmente denso para as relações de poder" (FOUCAULT, 1976, p. 136). Essa especificidade da sexualidade se explica por sua 
"instrumentalidade", quer dizer, ela é "utilizável para um grande número de manobras" e pode ainda servir de "ponto de apoio, de charneira às estratégias às mais variadas" (FOUCAULT, 1976, p. 136). Fora de questão, para Foucault, de fazer um levantamento exaustivos dessas estratégias. O que interessa para ele é colocar em relevo aquelas (que não irei aqui reproduzir) que, incidindo diretamente sobre o corpo, foram capazes de produzir um novo dispositivo, ou seja, o "dispositivo de sexualidade", com o qual foi possível transformar o corpo em um objeto de conhecimento, produzir sobre ele um saber que esteve (ou está) a serviço de sua dominação e controle. Eis como Foucault o define:

É o nome que se pode dar a um dispositivo histórico: não realidade inferior sobre a qual exerceríamos um controle difícil, mas grande rede de superfície onde a estimulação dos corpos, a intensificação dos prazeres, a incitação ao discurso, a formação dos conhecimentos, o reforço dos controles e das resistências, se encadeiam uns aos outros, segundo algumas grandes estratégias de saber e de poder (FOUCAULT, 1976, p. 139).

Vou passar ao largo do complexo movimento argumentativo que Foucault irá realizar para demonstrar a existência desse dispositivo e como ele atua. Para mim, o que interessa é insistir que ele atua sobre o corpo, isto é, gostaria de chamar a atenção para sua dimensão física. Certamente, o corpo investido torna-se objeto de saber, o que significa que essa politização do corpo não o restitui em sua naturalidade original; é justamente o contrário. O dispositivo de sexualidade é produzido a partir do corpo; não é extraído dele como se revelasse sua verdade recôndita por meio de um discurso científico que finalmente foi capaz de atingir sua essência. A esse dispositivo corresponde, então, uma "intensificação do corpo", "sua valorização como objeto de saber e como elemento nas relações de poder" (FOUCAULT, 1976, p. 141). Contudo, o dispositivo de sexualidade apenas pode operar essa intensificação na medida em que o corpo é a superfície em que vão se encontrar o que é da ordem individual e o que é da ordem coletiva. O corpo ou o sexo? Foucault afirma que o sexo é a "charneira dos dois eixos ao longo dos quais se desenvolveu toda a tecnologia política da vida", e que ele é ao mesmo tempo "acesso à vida do corpo e à vida da espécie" 
(FOUCAULT, 1976, p. 191-2). Em seguida vou tentar explicar melhor em que consistem esses "eixos" de que fala Foucault. Por enquanto, quero apenas observar que o sexo não pode assegurar esse acesso se não fosse ele mesmo uma construção, um dispositivo imposto sobre o corpo sob determinadas condições históricas, o qual deve ser problematizado por uma história da sexualidade. Um dispositivo que nos faz estabelecer com os prazeres do corpo não uma sofisticada relação de intensificação (como a ars erotica oriental), mas que nos leva a interrogar sobre nossa verdade (na forma de uma scientia sexualis). Porém, Foucault não nos deixa esquecer o laço que une o sexo e a vida e é por essa via que ele poderá realizar o último movimento argumentativo de A vontade de saber: o dispositivo de sexualidade introduz uma forma de poder radicalmente nova, a saber, uma tomada do poder sobre a vida. Finalmente, fica mais claro como a sexualidade se articula sobre o corpo: não é apenas o prazer que explica a captura política do corpo por meio de um discurso de verdade; o corpo é também o lugar em que a vida desdobra sua potência, individual e coletivamente ${ }^{6}$.

\section{Uma Política da Vida}

Para referir-se a esse fenômeno tipicamente moderno, o aparecimento de um poder que se "encarrega da vida" (FOUCAULT, 1976, p. 188), que Foucault vai utilizar dois termos de enorme fortuna crítica: biopoder e biopolítica. Em certa medida, eles são o ponto de chegada da analítica do poder em seu primeiro momento, integrando sob o nome de "anátomo-política" os trabalhos anteriores acerca do poder disciplinar e sob o nome de "biopolítica da população" o novo campo de análise descortinado a partir da história da sexualidade.

As disciplinas do corpo e as regulações da população constituem os dois polos em torno dos quais se desdobrou a organização do poder

6 Sobre este último ponto, uma passagem do curso de 1976 coloca a questão em termos precisos: "Nós estamos então em um poder que se encarregou do corpo e da vida, ou que tomou, se vocês quiserem, a vida em geral, com o polo do lado do corpo e o polo do lado da população" (FOUCAULT, 1997, p. 225-6) 
sobre a vida. A implementação no curso da Idade Clássica dessa grande tecnologia de dupla face - anatômica e biológica, individualizante e especificadora, voltada para as performances do corpo e olhando para os processos da vida - caracteriza um poder cuja mais alta função de agora em diante não é talvez mais matar, mas investir a vida de uma ponta a outra (FOUCAULT, 1976, p. 183).

Esse investimento da vida "de uma ponta a outra" não somente denuncia a presença do poder nos diversos âmbitos da sociedade, mas também a constituição de um novo objeto de poder: a população. Mas em que consiste, mais exatamente, a emergência da população?

O homem ocidental aprende pouco a pouco o que é ser uma espécie viva em um mundo vivo, ter um corpo, condições de existência, probabilidades de vida, uma saúde individual e coletiva, forças que podemos modificar e um espaço onde podemos reparti-las de maneira ótima. Pela primeira vez, sem dúvida, na história, o biológico se reflete no político (FOUCAULT, 1976, p. 189).

A partir daí, Foucault poderá retomar suas críticas ao poder de soberania, mostrando como sua economia política obedece a princípios muito distintos daqueles que regem a biopolítica. Essas diferenças são sintetizadas nas injunções "fazer morrer e deixar viver", que caracteriza o poder do soberano, e "fazer viver e deixar morrer", que especifica o biopoder. Mais uma vez, vou me furtar ao trabalho de reproduzir as nuances da argumentação de Foucault, preferindo ater-me exclusivamente ao elemento original que o livro apresenta nessa parte final.

Se a concepção da política em termos de "estratégia", jogos de força", "táticas" expressava uma clara ruptura com o discurso jurídico-político - ou ao menos a recusa obstinada de aceitá-lo como referencial teórico maior para entender a política moderna - a política entendida como "gestão da vida da população" repete esse mesmo gesto por uma via nova. A emergência da "população" requereu o desenvolvimento de uma nova tecnologia política originalmente estranha ao instrumental jurídico. Mais ainda, uma tecnologia até mesmo capaz de mobilizar o discurso da lei para atingir seus objetivos (FOUCAULT, 1976, 
p. 190). O aparecimento da "população", contudo, não é devidamente compreendido quando desconhecemos o que Foucault entende pelo termo em 1976.

Antes de tudo, "população" tem uma acepção biológica, como vimos. E parece-me fundamental insistir sobre essa dimensão, uma vez que é justamente o que explicita a noção de biopolítica. Sempre atendo-se às "empiricidades", Foucault acredita que a explosão demográfica da Europa no século XVIII, quer dizer o aparecimento da população como uma realidade específica, colocou um problema completamente novo no campo do exercício do poder: como gerir a população de modo a aumentar suas riquezas, sua duração de vida, sua saúde? Essa questão estará na origem de uma nova tecnologia política que Foucault chamará mais tarde, no curso de 1978, de tecnologias de governo ou simplesmente de "governamentalidade". Em 1976, porém, o estágio da pesquisa permite apenas assinalar o surgimento dessa nova figura e suas implicações imediatas sobre o sistema político: com a população, o ser humano é capturado pelas tecnologias de poder na condição de ser vivo. Gostaria de destacar duas consequências desse fenômeno: a primeira é que a população está sujeita à "normalização", isto é, o ser humano como membro de uma espécie é suscetível à "regulação"; a segunda consequência - na verdade deduzida da primeira - é a de que o biopoder, exercido sobre a população, não pode deixar de incidir incessantemente sobre o corpo, dispensando os clássicos mecanismos que asseguravam uma mediação entre os seres humanos e o poder. Isso coloca em um novo patamar a "materialidade" do poder a que já fiz alusão. Em ambos os casos, vemos que Foucault reformula sua crítica ao poder de soberania.

No que diz respeito à "normalização", o aparecimento do biopoder sobre a população significou o aumento da importância do "jogo da norma" sobre o sistema jurídico da lei. Foucault afirma o seguinte:

A lei não pode não estar armada, e sua arma, por excelência, é a morte; àqueles que a transgridem, ela responde, ao menos a título de último recurso, com essa ameaça absoluta. A lei sempre se refere ao gládio. Mas um poder que tem por tarefa encarregar-se da vida terá necessidade de mecanismos contínuos, reguladores e corretivos. Não se trata mais de 
fazer atuar a morte no campo da soberania, mas de distribuir o ser vivo em um domínio de valor e de utilidade. Um tal poder tem de qualificar, medir, apreciar, hierarquizar, antes do que se manifestar em seu brilho mortífero; ele não tem de traçar a linha que separa, dos súditos obedientes, os inimigos do soberano; ele opera as distribuições em torno da norma. Eu não quero dizer que a lei se apaga ou que as instituições de justiça tendem a desaparecer; mas que a lei funciona sempre mais como uma norma, e que a instituição judiciária se integra cada vez mais a um contínuo de aparelhos (médicos, administrativos etc.) cujas funções são sobretudo reguladoras. Uma sociedade normalizadora é o efeito histórico de uma tecnologia do poder centrada sobre a vida (FOUCAULT, 1976, p. 189-90).

Desnecessário aqui analisar demoradamente os sentidos que a noção de "norma" adquire nos trabalhos de Foucault no contexto de sua analítica do poder ${ }^{7}$. A única coisa que gostaria de assinalar é que a partir dela Foucault poderá não somente marcar as diferenças entre o biopoder e o poder soberano, mas aprofundar aquelas que separam a biopolítica do sistema disciplinar. Como ficará claro no curso de 1978, os dispositivos de segurança não podem atuar sem dispor de um conhecimento acerca da "natureza das coisas", um saber acerca da realidade do fenômeno da população que capacita a agir sobre ela. De modo muito sucinto, poderíamos dizer que, diferentemente do que ocorre no sistema disciplinar, a norma não é um dado anterior àquilo sobre o que ela deve se aplicar: ela é, na verdade, "um jogo no interior das normalidades diferenciais" (FOUCAULT, 2004, p. 60-1). Foucault está convencido de que a condição para que o "poder normalizador", cujo objeto é a população, seja efetivo é apoiar-se sobre ela a partir de um saber extraído de sua realidade. É o fulcro mesmo da ideia de "governar" que aí se constitui. Afinal de contas, governar não é impor sobre as coisas uma vontade, não consiste em dominá-las por meio de um instrumental, de mecanismos, de dispositivos que the seriam essencialmente estranhos. Governar é "conduzir" e, por isso, não pode

7 Para um melhor conhecimento do tema, vale a pena ler os livros de François Ewald (2000) e de Márcio Alves da Fonseca (2002). 
desconsiderar o modo próprio, a regularidade, as constâncias daqueles que sob sua influência. Em última instância (mas aqui já estamos muito longe de $A$ vontade de saber), governar não é possível sem que se reconheça a "liberdade" dos governados (FOUCAULT, 2004, p. 50).

Tomada nessa chave, a questão da norma nos introduz em uma dimensão completamente nova do poder e que será o fulcro da governamentalidade. Mas Foucault não poderia ter formulado o problema nesses termos se não partisse da noção de população, como ele próprio afirmou (FOUCAULT, 2004, p. 91). Mas para isso, foi preciso que a noção de população sofresse uma significativa reformulação, não podendo mais ser reduzida a sua dimensão biológica: se em 1976 ele havia dito que a biopolítica concerne ao ser humano em sua dimensão vital, em 1978 fará questão de indicar que a vida humana não pode, como simples dado bruto, em sua "nudez", ser tomada como objeto de investimento do poder. A população certamente envolve uma dimensão biológica, e, sem dúvida, está ligada à esfera da necessidade, mas é, sobretudo, um lugar de exercício do poder em que natureza e artifício se entrecruzam. Por razões evidentes, não posso prolongar aqui as considerações sobre a evolução do tema da população em Foucault, mas o que interessa sublinhar é que, por referência a ela, podemos ver como A vontade de saber, em sua parte final, é ao mesmo tempo um ponto de chegada e um recomeço da pesquisa genealógica ${ }^{8}$.

O último ponto que gostaria de comentar (e aí serei muito breve) é aquele que concerne à intervenção sobre o corpo (individual e coletivo). Trata-se de enfatizar que o biopoder, ao encarregar-se da vida do ser humano - ou de tomar o ser humano na condição de ser vivo - visa diretamente seu corpo. Certamente, o poder disciplinar, como havia mostrado Foucault nos anos anteriores, também atua dessa forma. Mas o que vemos em $A$ vontade de saber é que a "tomada" sobre o corpo não se desvencilha de uma mudança no status do sujeito: ao invés de entrar na cena política como sujeito de direito, ele aí é inscrito como ser vivo. E esse processo apenas pôde se realizar quando a vida

8 Vale notar que é exatamente nesses termos que Richard Lynch interpreta o livro (LYNCH, 2013, p. 154), o que coaduna perfeitamente com o caráter programático que Foucault quis atribuir ao texto. 
passou a ser investida pelo poder, a vida que se encontra em cada um de nós. Consequentemente, é destituída a mediação assegurada pela lei e pelo direito. Pela primeira vez na história a exposição direta do ser humano ao poder está integrada nos próprios mecanismos de poder. Como Foucault demonstrou exaustivamente, não se trata mais do poder tomar o corpo do sujeito no momento da morte, para destruí-lo, aniquilá-lo e assim manifestar sua potência; trata-se de assumir a tarefa de investi-lo sem cessar, de modo a assegurar a manutenção da vida e seu incremento. Posteriormente, Foucault irá refinar seu ponto de vista, entendendo que esse investimento sobre o corpo da população e do indivíduo não necessitam ser diretos, isto é, o poder governamental é tão mais eficaz quanto mais capaz é de agir sobre o "meio" (FOUCAULT, 2004, p. 22-3). Mas a novidade absoluta está no fato de aquilo que qualifica politicamente o indivíduo não é a propriedade, não é o pertencimento a determinado grupo social e não é o direito. $\mathrm{O}$ que o qualifica - algo impensável para Aristóteles - é o simples fato de nascer e fazer parte de uma população. Entendamos bem: "qualificar" significa "estar inserido nas relações de poder", sujeito à violência que delas pode resultar, como também capaz de modificá-las em favor da liberdade.

\section{Considerações finais}

Neste curto comentário sobre $A$ vontade de poder desejei destacar dois de seus aspectos que me parecem mais originais. Mais especificamente, meu objetivo era mostrar como Foucault, nesse livro, produz uma grande inovação no campo do pensamento político, sobretudo porque apresenta uma crítica bastante amadurecida ao conceito clássico de soberania, por um lado, e, por outro, formula uma concepção de poder a partir da análise de seu exercício efetivo, isto é, no registro da "empiricidade". De acordo com essa concepção, o poder deve ser entendido como "multiplicidade das relações de forças" (ou ainda “jogo de forças") imanente ao domínio político. Quis então compreender de que modo essa perspectiva a qual destaca a natureza conflitiva, 
estratégica do poder é refratária às visões totalizantes do campo da política. As ideias de "multiplicidade", de "luta" e de "jogo" apontam a natureza fragmentária desse campo e, ao mesmo tempo, permitem compreender sob uma luz diferente a "positividade" do poder, vale dizer, seu caráter "material" e "produtivo". O outro ponto que pretendi desenvolver, sempre visando colocar em evidência o caráter inovador do livro de Foucault, foi a própria noção de biopolítica, dando ênfase ao tema da população. Interessava-me mostrar então que, ao assinalar o surgimento de um novo poder que se encarrega da vida, que toma o ser humano como ser vivo membro de uma espécie, que se incide sobre uma população, entendida originalmente em um sentido fortemente biológico, Foucault dá um passo definitivo em sua crítica à concepção jurídico-discursiva do poder e coloca em um novo patamar a ideia de "positividade". Evidentemente, ele faz mais do que isso: ele identifica em nossa modernidade política algo radicalmente novo, isto é, a inscrição do ser humano na política sob a condição de ser vivo.

De meu ponto de vista, esses dois pontos - da "multiplicidade das relações de forças" ao "biopoder" - balizam o percurso que Foucault perfaz em $A$ vontade de saber, culminando em uma visão da política inegavelmente original. Certamente, as análises de Foucault convergem com as interpretações de outros autores, sobretudo com as de Hannah Arendt no que diz respeito à crítica à concepção jurídica e à preponderância do tema da vida na experiência política moderna9. No entanto, seria ilegítimo ou mesmo injusto querer diminuir o impacto da analítica do poder tornando-a devedora de uma forma de pensamento que lhe é estranha. Por acreditar nisso, também me recusei a sugerir qualquer ascendência, influência ou legado no trabalho de Foucault. Não que eles não existam (afinal de contas o próprio filósofo, em determinadas ocasiões, os reivindicou), mas seriam de pouco auxílio quando está em questão adentrar, mesmo que por um tempo breve, o novo terreno desbravado por Foucault.

9 Dos vários trabalhos dedicados à aproximação entre Arendt e Foucault não posso deixar de mencionar o livro de André Duarte, Vidas em risco (2010). 


\section{Referências}

ARISTOTELES. Les politiques. Trad. de P. Pelegrin. Paris: Flammarion, 1993.

AUDIER, S. Penser le "Néolibéralisme". Le moment néoliberal, Foucault et la crise du socialisme. Lormont: Le Bord de l'Eau, 2015.

DELEUZE, G. Foucault. Paris: Les Éditions de Minuit, 1986.

DUARTE, A. Vidas em risco. Crítica do presente em Heidegger, Arendt e Foucault. Rio de Janeiro: Forense Universitária, 2010.

EWALD, F. Foucault, a norma e o direito. Trad. de A. F. Cascais. Lisboa: Vega, 2000.

FONSECA, M. A. Foucault e o direito. São Paulo: Max Limonad, 2002.

FOUCAULT, M. Archéologie du savoir. Paris: Gallimard, 1969.

FOUCAULT, M. Surveiller et punir. Paris: Gallimard, 1975.

FOUCAULT, M. Histoire de la sexualité 1. La volonté de savoir. Paris: Gallimard, 1976.

FOUCAULT, M. “Les Rapports de Pouvoir à l'Intérieur des Corps". In: Dits et Écrits. v. III (texto 197). Paris: Gallimard, 1994.

FOUCAULT, M. Il faut défendre la société. Cours su Collège de France. 19751976. Paris: Gallimard/Seuil, 1997.

FOUCAULT, M. Sécurité, territoire, population. Cours su Collège de France. 1977-1978. Paris: Gallimard/Seuil, 2004.

FOUCAULT, M. O poder psiquiátrico. Curso dado no Collège de France. 19731974. Trad. de E. Brandao. São Paulo: Martins Fontes, 2006.

FOUCAULT, M. La société punitive. Cours su Collège de France. 1972-1973. Paris: Gallimard/Seuil, 2013.

FOUCAULT, M. Théories et instituitions pénales. Cours su Collège de France. 1972-1973. Paris: Gallimard/Seuil, 2015a. 
FOUCAULT, M. Qu'est-ce que la critique? Suivi de La culture de soi. Paris: Vrin, 2015b.

LYNCH, R. "Reading the History of Sexuality. Volume 1". In: FALZON, C; O'LEARY, T; SAWICKI, J. (ed). A companion to Foucault. Chichester: WileyBlackwell, 2013.

SKORNICKI, A. La grande soif de l'État. Foucault avec les sciences sociales. Paris: Les Prairies Ordinaires, 2015.

VEYNE, P. Foucault. Sa pensée, sa personne. Paris: Albin Michel, 2008.

Recebido: 20/09/2016

Received: 09/20/2016

Aprovado: 30/10/2016

Approved: 10/30/2016 